\title{
Effect of multiple impacts on protective properties of external hip protectors
}

\author{
Tatjana Bulat ${ }^{\prime}$ \\ Shawn Applegarth' \\ Stuart Wilkinson ${ }^{2}$ \\ Shirley G Fitzgerald' \\ Shahbaz Ahmed' \\ Patricia Quigley' \\ 'VISN 8 Patient Safety Center \\ of Inquiry, Tampa, FL, USA; \\ ${ }^{2}$ University of South Florida \\ Department of Mechanical \\ Engineering, Tampa, FL, USA
}

Correspondence:Tatjana Bulat VISN 8 Patient Safety Center of Inquiry, I 605 N. Nebraska Ave, Tampa, FL, USA

Tel + I 8135583923

Fax + I 8135583990

Email Tatjana.Bulat@va.gov

\begin{abstract}
A variety of external hip protectors are available on the market but no standards for their performance exist and it is unknown if their properties change after repeated fall impacts. The purpose of this study was to determine if protective properties change in different types of new (unused) hip protectors after repeated, simulated falls. Five hip protector brands were chosen to represent different products available on the market and the two mechanisms employed in reducing the force of an impact (shunting or absorbing). Ten pairs of each type ( 20 pads for each brand) were tested using a 1.8-m Instron Dynatup $9250 \mathrm{HV}$ vertical impact testing tower. The impact testing system was specifically designed for this study by creating a simulated trochanter to provide more accurately a impact area similar to that of a real hip bone. The hip protectors were impacted once a day for 3 consecutive days. Repeated impacts demonstrated the pads' decreased ability to either absorb or shunt force in all types of hip protectors. However, the mean forces were still in the protective range (force below fracture threshold of $3100 \mathrm{~N}$ ) for 3 of the 5 brands tested after 3 impacts. The protective properties of external hip protectors do degrade after repeated impacts. The degree of degradation differs from brand to brand. Regardless of type, most pads were still able to bring the force of impact below the fracture threshold of 3100 N. Future studies need to address the issue of durability of different types/brands of hip protectors after repeated laundering and fall impacts to determine when should they be replaced. Additionally, a national or international standard needs to be developed against which the performance of different brands of hip protectors can be compared.
\end{abstract}

Keywords: hip protectors, fall impacts, protective properties, hip fracture

\section{Introduction}

One of the most serious consequences of a fall is a hip fracture. In most cases, the immediate cause of hip fracture is a lateral fall with direct impact on the greater trochanter of the proximal femur (Greenspan et al 1998). External hip protectors are girdle-like devices, with shells made of polyurethane (Kannus et al 2000; Rubenstein 2000); multiple types of hip protectors are available on the market and can be divided into soft shell hip protectors that absorb the energy and redistribute the force of fall, hard shell hip protectors that shunt the energy of the impact into the surrounding soft tissues, and hybrid models that combine the hard and soft shell (Holzer and Holzer et al 2007). Evidence supports the use of hip protectors to prevent hip fractures when they are worn (Ekman et al 1997; Cameron et al 2000; Kannus et al 2000) in a nursing home population (Sawka et al 2005), but evidence in other situations has been mixed (Parker et al 2006). Recently, a number of randomized trials in nursing homes and in community-living elderly found hip protectors ineffective (Cameron et al 2002, 2003; Van Schorr et al 2003; Birks et al 2004). However, the validity of these studies was in question because patient adherence was low and durability issues were not taken into account (Cummings and Weiss 2003; Bulat and Quigley 2003; Honkanen 2003; Kiel et al 2007). No study, to date, has assessed the protective properties over time 
and how they may be affected by repeated impacts from falls or launderings. In this study, we wanted to test different models of hip protectors, in vitro, to determine what happens to their protective properties after multiple impacts (simulated falls).

\section{Methods}

A laboratory simulation of a human fall is a complex and difficult scenario to create. The primary focus of this testing system was on the applied force to the outside of the hip protector. This testing system used an applied force equal to that of a real person falling over onto a hip protector. While this system may not represent the exact human dynamic found during a fall, it does represent a highly repeatable, laboratory-controlled measuring method that uses a realistic applied impact force.

\section{Protectors tested}

Hard plastic shell ("hard type"), soft foam pads ("soft type"), and a hybrid of the hard and soft ("hybrid") type pads that were available on the market were tested in this study. The hip protectors were put into groups of 20 pads (10 pairs) and were randomly classified as Hip Protector A (soft), Hip Protector B (hybrid), Hip Protector C (hard), Hip Protector D (hard), and Hip Protector E (soft).

\section{Testing system}

To conduct the impact experiments, a 1.8-m Instron Dynatup $9250 \mathrm{HV}$ vertical impact-testing machine was used (Figure 1). This testing device can collect a plethora of data during an impact and send it to a PC for both graphical and numerical analysis. A $4450 \mathrm{~N}(2,200 \mathrm{~kg})$ piezoelectric load cell was chosen to acquire the force data due to its high accuracy in force readings $( \pm 3 \%$ ). The load cell is positioned directly behind an impact striker and provides numbers that directly correspond to the force seen passing into the hipbone. The weighted crosshead of the machine can be moved vertically and released from any desired height along the rails. The impact system was calibrated in several ways to assure data confidence. A software correction algorithm was run to adjust for the effects of the friction created between the crosshead and the track. Further tests were run to confirm that the velocities were measured accurately. Finally, the crosshead was weighed between each experiment so the corresponding energy and force values would be computed correctly.

Measurements were taken of the greater trochanter from an adult skeleton and incorporated into the design of a new impact striker. This new striker was custom made in the

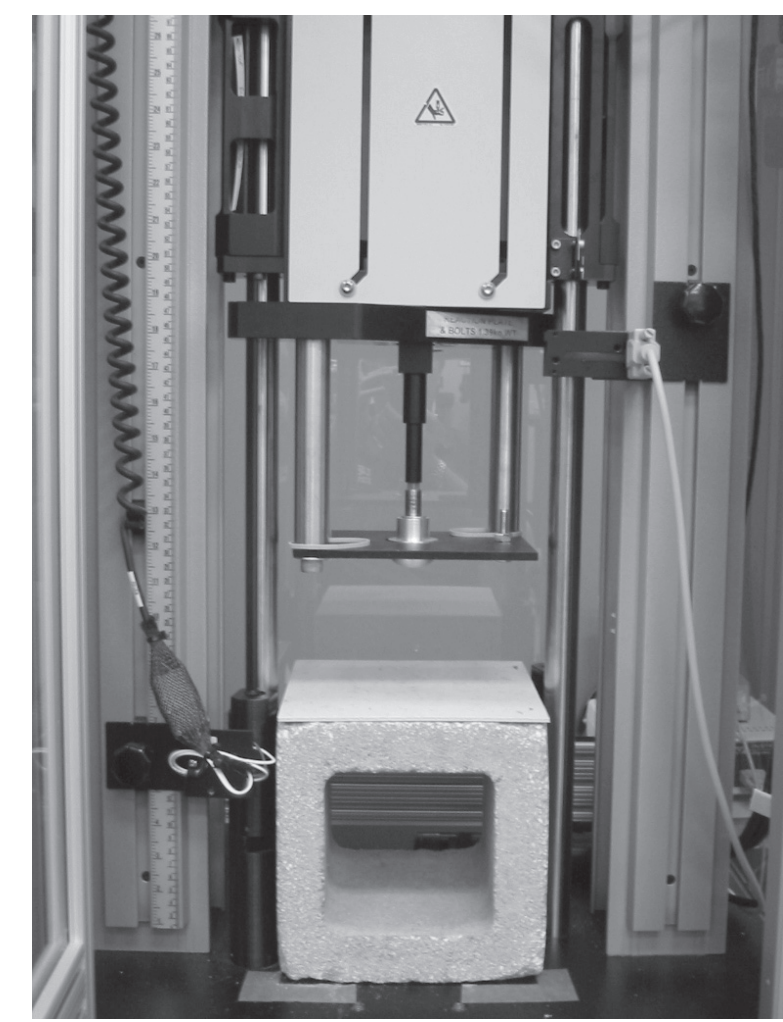

Figure I Instron impact testing machine.

laboratory to simulate closely the impact area of the greater trochanter found in the average adult. The entire load cell and striker set-up is depicted in Figure 2. The head of the striker protruded through a plate that held each hip protector pad in place.

A concrete block with a linoleum tile overlay was chosen for the impact surface, because this type of flooring is common in hospital/healthcare settings.

\section{Testing parameters}

Laboratory impact experiments performed in this study utilized an applied impact force of 17,000 N, which matched the mean force observed on the outside of hip protectors of human volunteers during a fall (Wiener et al 2002). This $17,000 \mathrm{~N}$ force was applied to the outside of each hip protector in order to measure how much force passes into the simulated hip bone. The testing system parameters used to obtain

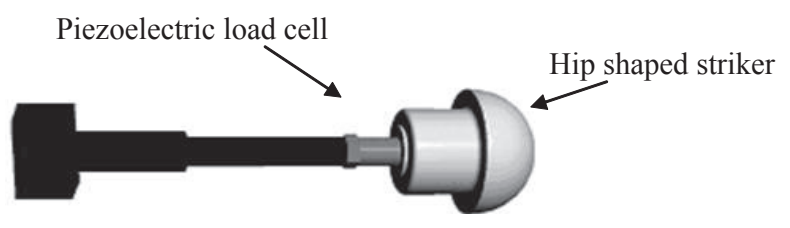

Figure $\mathbf{2}$ Load cell/striker system. 
this impact force, and thus used in all the experiments, were a crosshead mass of $8 \mathrm{~kg}$ and a drop height of $0.33 \mathrm{~m}$.

The baseline hip fracture force referenced in this study was $3100 \mathrm{~N}$, which is considered to be the average force needed to break the proximal femur of elderly women with a mean age of 71 years (Kannus et al 1999). This force can vary highly from person to person based on many factors including bone structure and the dynamics of the fall scenario.

\section{Testing procedure}

All hip protectors were cut away from their respective garments to avoid interference within the testing machine. A 5-mm layer of low density polyethylene foam (LDPE), having a density of $0.04 \mathrm{~g} / \mathrm{cm}^{3}$, was placed between the protector and the impact striker. This 5-mm foam layer is a typical skin and soft tissue simulant and was used in previous impact studies (Wiener et al 2002). A new layer was used after each subsequent impact.

A hip protector-positioning jig was created to properly align the pads on the testing plate, assuring that each protector was placed in the same location for each repeated hit. Each protector was securely held in place with an elastic fastening tie. All hip protectors were given a 24-hour recovery time between impacts.

\section{Analysis}

For each type of protector and for each impact trial, means and standard deviations were calculated. An overall mean and standard deviation were also calculated for all three trials. Although right and left pads were tested for each pair of protectors, the forces that each side would endure were not correlated, and thus it was decided to leave them as independent entities. A survival analysis was then completed which examined across protector types and impact over each trial. Protectors were censored when the force exceeded 3,100 N.
Alpha level was set a priori at 0.05 and all analysis was completed in SPSS, version 11.

\section{Results}

The data from the impact experiments presented in Table 1 illustrates the amount of force that passes into the hip protector and the greater trochanter. A direct comparison of the mean forces indicates there is a decrease in the hip protectors' ability to either shunt or absorb force of impact with repeated impacts.

The mechanism of protection (hard/soft/hybrid) seems to have had little bearing on a pad performance. Figure 3 shows the mean force measured for all three impacts for each type of hip protector.

Hip Protectors A, B, and C remained below both the sensor capacity $(4,450 \mathrm{~N})$ and the imposed fracture limit of 3,100 N. Hip Protector D produced results very close to the fracture threshold limit after Impact $1(2,981 \mathrm{~N})$ and far exceeded the imposed limit after Impact $2(4,635 \mathrm{~N})$. Hip Protector E produced results $(3,796 \mathrm{~N})$ well above fracture threshold after Impact 1. Therefore, data collection for these hip protectors (D and E) was suspended early due to the large numbers of pads approaching and exceeding both sensor and fracture capacities. The survival analysis revealed that after three impact sessions, $87 \%$ of soft hip protectors (A), $76 \%$ of hard hip protectors (C), and $56 \%$ of hybrid hip protectors (B) were still below the hip fracture threshold. Hip protectors D and E did not survive multiple impacts. Impact testing between protectors A, B, and C did not differ significantly. Protectors D and E were significantly more likely to go beyond the hip fracture threshold.

All hip protectors showed signs of degradation over multiple impacts. The degradation for each protector was variable, as the presented data indicate. Hip Protectors A and B showed the greatest decrease in ability to protect, with a $97 \%$ and $83 \%$ decrease in force reduction ability, respectively,

Table I Mean force (N) allowed into the simulated hipbone for each of the three impacts*

\begin{tabular}{llllll}
\hline Parameter & $\begin{array}{l}\text { Hip Protector A } \\
\text { “soft type" }\end{array}$ & $\begin{array}{l}\text { Hip Protector_B } \\
\text { “hybrid type" }\end{array}$ & $\begin{array}{l}\text { Hip Protector C } \\
\text { “hard type” }\end{array}$ & $\begin{array}{l}\text { Hip Protector D } \\
\text { "hard type" }\end{array}$ & $\begin{array}{l}\text { Hip Protector E } \\
\text { "soft type” }\end{array}$ \\
\hline Impact I mean force (N) & 964.500 & 1390.487 & 1813.792 & 2981.256 & 3796.216 \\
Impact 2 mean force (N) & 1683.837 & 1888.716 & 2112.221 & 4635.660 & No data \\
Impact 3 mean force (N) & 1897.888 & 2543.710 & 2251.912 & No data & No data \\
Mean load (N) & 1515.408 & 1940.972 & 2059.310 & 3206.856 & 3796.216 \\
Minimum load (N) & 829.685 & 948.225 & 1261.453 & 2009.295 & 1567.640 \\
Maximum load (N) & 3348.321 & 4242.947 & 3709.543 & 4896.225 & 4890.584 \\
SD (N) & 620.242 & 860.001 & 543.272 & 782.731 & 966.320 \\
\hline
\end{tabular}

* Lower force numbers indicate a more effective pad. 


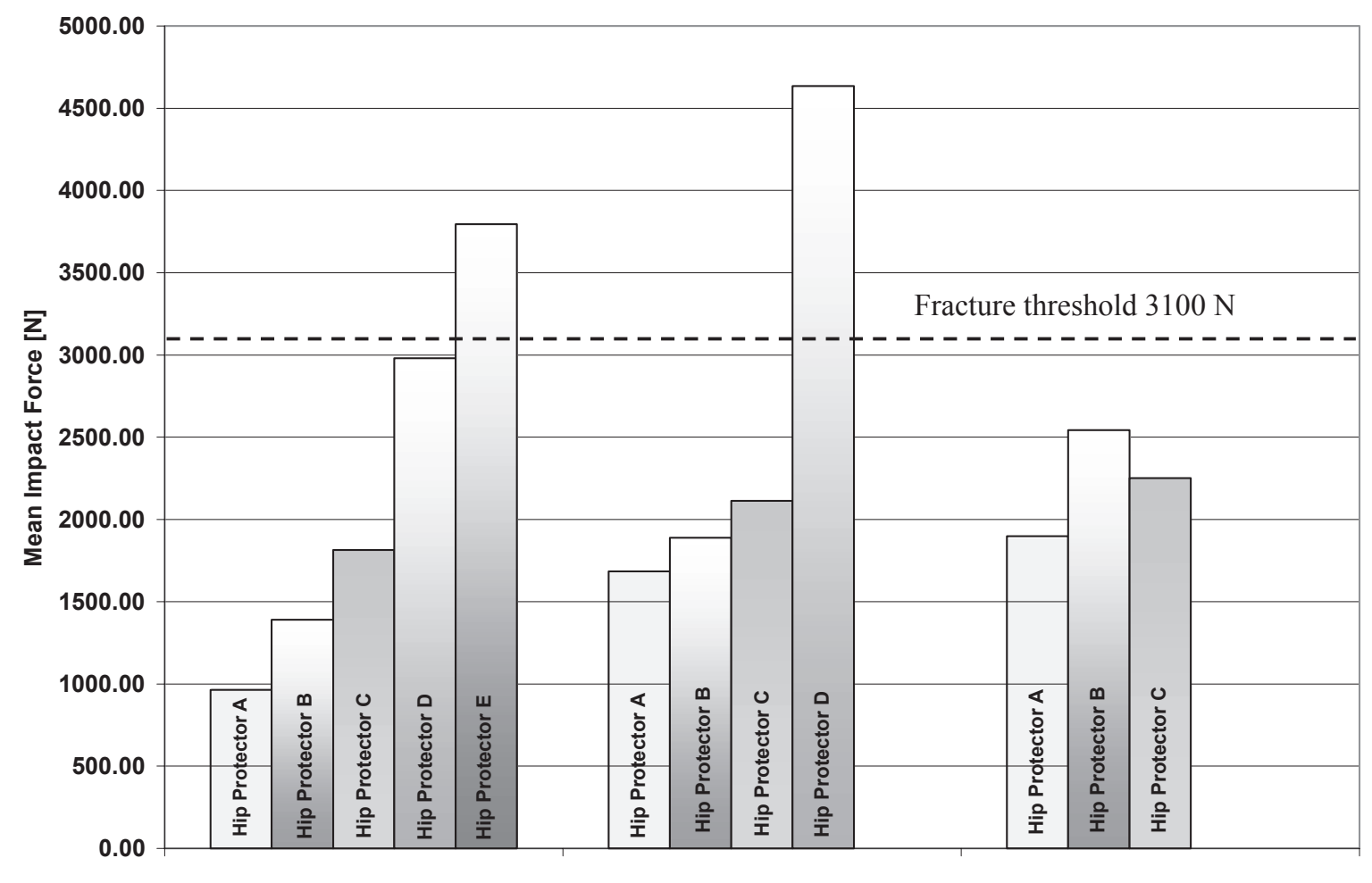

Impact 1

Impact 2

Impact 3

Figure 3 Mean force measured for hip protectors across impacts I, 2, and 3.

between impacts 1 and 3, but still stayed below the fracture threshold. Hip Protector B fared well through the first two impacts but experienced a sudden $35 \%$ force propagation between impacts 2 and 3, resulting in the worst mean of Impact 3 (2,543 N) of the pads tested. Hip Protector C was the most consistent pad tested, experiencing only a $24 \%$ decrease ability to protect between Impact 1 and 3 .

\section{Discussion}

The hip protectors' force attenuation or protective properties diminished after multiple impacts. However, the mean force that passes into the greater trochanter was still below the study's hip fracture threshold of $3100[\mathrm{~N}]$ for three of the five brands of protectors tested. This results indicates that while indeed the hip protectors do degrade with multiple impacts, most still retain enough protective properties to shield a hip from fracture. Of the 60 samples tested for protectors A, B, and C, 9 produced a force greater than the 3,100 N threshold. Most of these sample "failures" occurred on the third and final impact. Conversely, 8 of the 19 pads tested for Hip Protector D and 14 of the 17 pads tested for Hip Protector E exceeded the fracture threshold after just 1 impact.

The data indicate that the mechanism by which hip protectors protect (hard shunting shell, soft absorbing pad) have little bearing when examining the effects of multiple impacts. The pad that produced the lowest mean in the study, across all impacts, was a soft type pad (Hip Protector A). There was only a 35\% difference in the mean of Hip Protector A (soft type) and Hip Protector C (hard type). For the two brands of hip protectors that preformed poorly one was a hard type and the other soft type hip protector (Hip Protector D and E). These data suggest that it is the individual design and materials used in each hip protector type that has the major bearing on how well they perform in vitro rather than a group effect (soft vs hard/hybrid).

Recently, a number of studies questioned the effectiveness of hip protectors for hip fracture prevention, especially in the community-living elderly. Patient acceptance and adherence with hip protector use over time is a problem and low adherence has been cited as an explanation for the lack of effectiveness. It could be postulated that, in addition to adherence, the lack of effectiveness observed in those studies might be due to changes in the protective biomechanical properties of these devices after prolonged use, which may include the effects of multiple impacts.

\section{Conclusion}

The evidence collected indicates that the protective properties of external hip protectors degrade to some degree after 
repeated impacts. The extent of degradation differs for each brand of hip protector tested regardless of the mechanism by which it protects (hard/soft/hybrid). However, most pads were still able to bring the force of impact below the fracture threshold of 3,100 N. This study adds further evidence that external hip protectors can decrease the force of the impact in vitro. Future studies need to address the issue of durability of different brands of hip protectors after repeated laundering/ impacts to determine when should they be replaced in order to provide continued protection against hip fractures. In addition, an international testing standard for hip protectors needs to be developed so that the external hip protectors could be tested under the same conditions and their performance compared (Kannus and Parkkari 2007). As our data suggest, they are not all created equal.

\section{Acknowledgments}

The work presented here was supported by grants from VA National Center for Patient Safety, Ann Arbor, Michigan and VISN 8 Patient Safety Center and James A. Haley VA Hospital, Tampa, Florida.

\section{Disclosures}

None of the authors has any conflicts of interest.

\section{References}

Birks YF, Porthouse J, Addie C, et al. 2004. Randomized controlled trial of hip protectors among women living in the community. Osteoporosis Int, 15:701-6.

Bulat T, Quigley P. 2003. External hip protectors and risk of hip fracture. JAMA, 290:883.

Cameron ID, Cumming RG, Kurrle SE, et al. 2003. A randomized trail of hip protector use by frail older women living in their own homes. Injury Prevention, 9:138-41.
Cameron ID, Stafford B, Cumming RG, et al. 2000. Hip protectors improve falls self-efficacy. Age Ageing, 29:57-62.

Cameron I, Venman J, Kurrle S, et al. 2002. Hip protectors in aged-care facilities: a randomized trial of use by individual higher-risk residents. Age Aging, 30:477-81.

Cummings P, Weiss NS. 2003. External hip protectors and risk of hip fracture. JAMA, 290:884.

Ekman A, Mallmin H, Michaelsson K, et al. 1997. External hip protectors to prevent osteoporotic hip fractures. Lancet, 350:563-4.

Greenspan S, Myers ER, Kiel DP, et al. 1998. Fall direction, bone mineral density, and function: risk factors for hip fracture in frail nursing home elderly. Am J Med, 104:539-45.

Holzer G, Holzer LA. 2007. Hip protectors and prevention of hip fracture in older persons. Geriatrics, 62:15-20.

Honkanen L. 2003. External hip protectors and risk of hip fracture. JAMA, 290:883-4.

Kannus P, Parkkari J. 2007. Hip protectors for preventing hip fracture. Editorial. JAMA, 298:454-55.

Kannus P, Parkkari J, Niemi S, et al. 2000. Prevention of hip fractures in elderly people with the use of a hip protector. NEJM, 343:1506-13.

Kannus P, Parkkari J, Poutala J. 1999. Comparison of force attenuation properties of four different hip protectors under simulated falling conditions in the elderly: an in vitro biomechanical study. Bone, 25:229-35.

Kiel DP, Magaziner J, Zimmerman S, et al. 2007. Efficacy of a hip protector to prevent hip fracture in nursing home residents. The HIP PRO Randomized controlled trial. JAMA, 298:413-22.

Parker MJ, Gillespie WJ, Gillespie LD. 2006. Effectivenss of hip protectors for preventing hip fractures in elderly peolpe: systematic review. $B M J$, 332(7541):571-4.

Rubenstein, L. 2000. Hip protectors. A breakthrough in fracture prevention. NEJM, 343:1562-3.

Sawka AM, Boulos P, Beattie K, et al. 2005. Do hip protectors decrease the risk of hip fracture in institutionsl and community-dwelling elderly? A systematic review and meta-analysis of randomized controlled trails. Osteoporos Int, 16:1461-74.

Wiener SL, Andersson GBJ, Nyhus LM, et al. 2002. Force reduction by an external hip protector on the human hip after falls, Clin Orthop Relat Res, 398:157-68.

Van Schorrn, Smit JH, Twisk JWR, et al. 2003. Prevention of hip fractures by external hip protectors. A randomized controlled trial. JAMA, 289:1957-62. 
